\title{
Sosyokültürel, Etik, Tıbbi ve İslami Perspektiften \\ Kız Çocuklarda ve Kadınlarda Sünnet
}

\author{
Female Circumcision from Sociocultural, Ethical, \\ Medical, and Islamic Perspectives
}

Öz

Bu çalışmanın amacı, kız/kadın sünnetinin sosyokültürel, tıbbi, etik ve dini/İslami olmak üzere dört ayrı perspektiften incelenmesidir. Günümüzde kadın sünneti Afrika'da uygulanmakta ve uygulama sıklığı ülkeden ülkeye değişmektedir. Tarih boyunca kadın sünnetine gerekçe gösterilen sosyokültürel nedenlerden hiçbirinin bilimsel geçerliliği yoktur. Kadın sünneti sıhhi hiçbir yarar sağlamaz, aksine, erken ve geç dönemde kadının fiziksel, ruhsal ve sosyal sağlığına ciddi bir darbe vurur. Cinsel sağlık ve mutluluk açısından ise, tam bir felaket tablosudur. Ancak konu ile ilgili bir uygulama olan "hoodectomy" bir istisna olup, kadın lehine olumlu sonuçlar veren bir müdahaledir. Kadın sünnetine etik perspektiften baktığımızda, genel kabul gören temel etik prensiplerin tümünün ihlal edildiğini görürüz. Son olarak İslami perspektiften bakıldığında, Kur'an'da kızların sünnetine mesnet teşkil edip hüküm çıkarılacak bir ayet olmadığı görülür. Kız sünnetinden bahseden hadisler de hadis ulemasınca zayıf bulunmuştur. Fetva vermeye mesnet olacak sıhhat ve kuvvette kabul edilmemişlerdir.

Anahtar Sözcükler. kız/kadın sünneti; ataerkil toplum; hoodectomy; İslam ve kadın sünneti

\section{Abstract}

This paper aims to address female circumcision (FC) from sociocultural, medical, ethical and religious/Islamic perspectives. FC is performed primarily in Africa today; its prevalence varies across countries. None of the sociocultural justifications developed historically for FC is scientifically valid. FC provides no health benefits, but, on the contrary, severely impairs the physical, psychological and social health of the victim in the short and long term. As for sexual health and satisfaction, the outcome is disastrous. Hoodectomy as another relevant surgical intervention, however, can be distinguished as an exception because it can be for the benefit of the woman. When we assess FC ethically, we see that all of the generally accepted, major principles of medical ethics are violated. Finally when we look at FC from an Islamic perspective, the Quran does not contain any verses to ground or adjudicate arguments on FC. The hadiths reporting about the justification of FC have been determined by the hadith scholars to be weak. They have not been accepted as sound justificatory sources that a fatwa can be based on.

Keywords: female circumcision; patriarchal society; hoodectomy; female circumcision and Islam

\section{M. İhsan Karaman}

İstanbul Medeniyet Üniversitesi, Tıp Fakültesi, Üroloji Anabilim Dalı

Geliş Tarihi /Received : 15.11.2016 Kabul Tarihi /Accepted: 14.04.2017

DOI: 10.21673/anadoluklin.266077

Sorumlu Yazar/Corresponding Author Prof. Dr. M. İhsan Karaman

İstanbul Medeniyet Üniversitesi Rektörlüğü, D-100 Karayolu, 98 34000 istanbul, Türkiye

E-mail:mikaraman@hotmail.com 


\section{Giriş}

Neredeyse MÖ 4000'den beri gözlenegelen bir gelenek olan kadın sünneti, genellikle ataerkil toplumların bağlı bulunduğu normlar ve değerlerle ilişkili görülmüştür. Bugün artık dünyanın sayılı ve belli bazı bölgelerinde uygulanmakta olup, bunlarda dahi uygulama sıklığı değişiklik göstermektedir. Bu oran, hepsi Afrika içinde olmasına rağmen Somali, Mısır, Gine, Etiyopya, Mali, Sudan, Eritre, Cibuti ve Sierra Leone'de \%70'in üzerindeyken, Gana, Nijer, Kamerun ve Uganda'da \%10'un altındadır. Afrika dışında, Irak, Yemen, Afganistan, Malezya ve Endonezya'da da kız ve kadınların sünnet edildiği bilinmektedir (1-5) (Resim 1).

Kadın sünneti ile ilgili bazı istatistiki veriler şöyle siralanabilir: Afrika ve Orta Doğu'daki 29 ülkede, 125 milyondan fazla kız ve kadın sünnetlidir. Genellikle bebeklik ile 15 yaş arasında uygulanır (6). Tüm kız sünnetlerinin \%18'i sağlık çalışanlarınca yapılır ve kızlarda sünnetin, özellikle Uzak Doğu ülkelerinde giderek daha medikalize olduğu bilinmektedir (7-10). Öte yandan, İngiltere'de dahi her yıl 15 yaş altı 20.000 kız sünnet edilme riskiyle karşı karşıyadır ve bu ülkede 66.000 kadın sünnetin uzun dönem zararları ile uğraşmaktadır $(8,11,12)$.

Ağırlıklı olarak Afrika'da uygulanan geleneksel kadın sünneti, genellikle, tıbbi eğitimi olmayan bir kadın sünnetçi tarafından yapılır. Çoğu kez anestezik ve antiseptik maddeler kullanılmaz ve işlem sıklıkla bıçak, makas, neşter, jilet ya da cam parçalarıyla gerçekleştirilir. İşlem sırasında doğal olarak şiddetli acı duyan çocuk, yardımcılar tarafından zorla ve bazen şiddet uygulanarak zapt edilir $(13,14)$.

$\mathrm{Bu}$ derlemede, kadın/kız sünnetini, sosyokültürel, tıbbi, etik ve dini/İslami olmak üzere dört ayrı perspektiften ele alıp irdeleyeceğiz (15).

\section{Kız Çocuklarda ve Kadınlarda Sünnet}

Batı literatüründe kız ve kadınlara uygulanan sünnet ile ilgili nomenklatür zaman içinde değişim göstermiş olup bugün İngilizce literatürde female circumcision (FC), female genital mutilation (FGM) ve female genital cutting (FGC) terimleri kullanılmaktadır. Ülkemizde terim yaygın olmasa da, "kadın sünneti" ve "kız sünneti” eş anlamlı kullanılmaktadır.

- Dünya Sağlık Örgütü dört tip kadın sünneti tanımlamıştır (14,16-18) (Resim 2):
- Tip 1: sünnet derisi ile birlikte klitorisi kısmen veya tamamen çıkarma-clitoridectomy

- Tip 2: klitorisle beraber küçük dudakları ve bazen büyük dudakların bir kısmını çıkarma-excision

- Tip 3: küçük ve büyük dudakları çıarıp kenarları dikerek, vajina girişini bir küçük delik haline getirme-infibulation

- Tip 4: tüm diğer zararlı genital girişimler: iğneleme, hızmalama, kazıma, yakma vb.

Kadınlarda uygulanan sünnetin kadın ve ailesi üzerinde bıraktığı etkiler, sosyokültürel, tıbbi, etik ve dini/İslami olmak üzere dört ayrı perspektiften ele alınarak incelenebilir (19-22).

\section{Sosyokültürel Perspektiften Kadın Sünneti}

Sosyokültürel perspektiften bakıldığında, tarih boyunca kadın sünnetine gerekçe olarak gösterilen nedenler arasında şunlar sayılabilir $(23,24)$ :

- Kızlı̆̆ın korunması ve onurlu bir evliliğin ön şartı olan bekaretin kanitı

- Kadını pislikten arındırma/temizleme

- Tam bir kadın olmanın ön şartı

- Kadında aşırı cinsel etkinliği önleme

- Kadını histeri veya aşırı mastürbasyon gibi bozukluklardan koruma

- Depresyon, cinnet ve kleptomani gibi mental sorunları önleme

- Cinsel isteği azaltıp, kadını herkesle cinsel ilişkide bulunmaktan alıkoyma

- Kadına yüksek toplumsal statü kazandırma

- Kısırlı̆ğ önleme

Hiç şüphesiz bu argümanların hiçbirinin bilimsel geçerliliği yoktur ve hepsi ancak birer "mit"tir (20).

\section{Tıbbi perspektiften kadın sünneti}

Kadın sünnetine tıbbi perspektiften bakıldığında ise, erkek sünnetinin kanıtlanan birçok yararına mukabil, kadın sünnetinde hiçbir sıhhi fayda yoktur $(17,24,25)$. Bilakis, kısa ve uzun vadede birçok sağlık problemi yaratır ki bir kısmı hayatla kabil-i telif değildir. Kadın sünnetinin tıbbi zararlarını erken ve geç dönem olarak iki grupta sıralayabiliriz $(17,24,26-28)$ :

Erken dönem:

- Şiddetli ağrı

- Sok

- Kanama

- Tetanos, kangren, HIV enfeksiyonu ve Hepatit B 


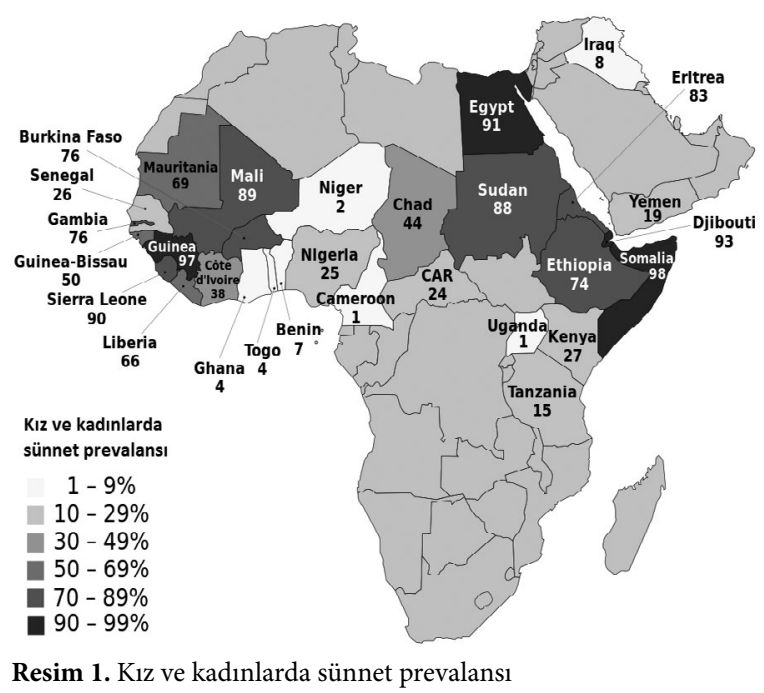

ve C dahil sistemik veya lokal enfeksiyonlar kapma

- İdrar yapamama

- İdrar kanalı veya bağırsak gibi komşu organlarda hasar/yaralanma

- Ölüm

Geç dönem:

Kronik vajina veya alt batın enfeksiyonları

Düzensiz adetler, ağrılı adetler, tıkanıklık

İdrarda zorlanma ve kalıcı idrar yolu enfeksiyonları

- İdrar kaçırma

- Böbrek yetmezliği

- Üreme sistemi hasarları ve kısırlık

- Apse, nedbe, kist oluşumu

- Gebelik komplikasyonları ve yenidoğan ölümleri

- Ağrılı ve zevksiz cinsel ilişki

- Psikolojik travmalar, isteksizlik, anksiyete ve depresyon

Kadın sünnetine, tıbbi perspektifin bir başka boyutu olan cinsel sağlık ve mutluluk açısından bakıldığında ise daha yıkıcı bir tabloyla karşılaşırız. Sünnette yok edilen başlıca bölgeler olan klitoris ve küçük dudaklar zengin sinir ağlarıyla çevrili olup cinsel uyarıya karşı duyarlıdır. Cinsel uyarı ve zevk, vajinal sekresyonu artırıp kadını -ve dolayısıyla erkeği de- rahat bir cinsel ilişkiye hazırlar. Bu duyarlı organların kaybı, vajinal kuruluğa ve ağrılı cinsel ilişkiye sebep olur; zevk alınmaz ve orgazma ulaşmak güçleşir (6). Sürekli tekrarlayan bu durum giderek cinsel soğukluk ve mutsuzluk yaratır. Önce kadında sonra erkekte cinsel fonksiyon bozukluğuna sebep olur. Bazı tiplerde uygulanan vaji- nal girişin daraltılması da, cinsel ilişki sırasında penis duhulünde ağrı ve kanamaya neden olur.

Bunlarla birlikte tıbbi açıdan kadın sünneti konusunda istisna teşkil eden bir uygulama vardır ki buna Ing. hoodectomy / clitoral hood reduction adı verilir (29-31). Bu müdahale yukarıdaki açıklamaların dışında bir irdelemeyi hak etmektedir.

Erkeklerde penis başını, kızlarda klitorisi örten deri parçasına İng. hood (Tr. kapüşon) adı verilir. Erkek sünnetinde çıkarılan parça budur. Bazı kızlarda bu deri fazla miktarda ya da ergenlikte çok gelişmiş ise klitorisi tamamen kaplar ve cinsel ilişkide penis ile klitoris arasinda yeterli temasa engel olabilir. Bu durumda duyarlılık azalır ve kadın ilişkiden zevk alamaz, orgazma ulaşamaz. Bu tip bir fazlalığın hoodectomy ile çıkarılması (bir anlamda sünnet edilmesi) ilişkideki zevki artırır ve orgazmı kolaylaştırır. Bu fazlalığın bulunması müdahale için gerçek bir tıbbi endikasyondur ve çıkarılması sağlığa yararlıdır.

Dünya Sağlık Örgütü de, 1979'da yayımladığg raporda bu gibi bir cerrahi müdahalenin zararsiz olduğunu şöyle ifade etmiştir: "Erkek sünnetinde olduğu gibi, klitorisin üzerindeki deriyi uzaklaştırma biçimindeki kadın sünnetinde de herhangi bir sıhhi zarar saptanmamıştır."

\section{Etik Perspektiften Kadın Sünneti}

Kadın sünnetine etik perspektiften baktığımızda, genel kabul gören temel etik prensiplerin tümünün ihlal edildiğini görürüz $(32,33)$ :

- Adalet

- Özerklik

- Yararlılık

\section{- Zarar vermeme}

Kadınlarda sünnet; güya birtakım toplumsal ya da ataerkil gerekler ifa edilirken kadının bedeninin tahrip edilmesi bakımından adalet, çoğunlukla kadının rızası olmadan ve hatta zorla gerçekleştirilmesi bakımından özerklik, kadına psikolojik ya da fizyolojik hiçbir sıhhi yarar sağlamaması bakımından yararlılık, hiçbir yarar sağlamadığı gibi bilakis kadını sakatladığı için de zarar vermeme prensibine aykırı bir girişimdir.

\section{İslami perspektiften kadın sünneti}

Kadın sünnetine son olarak İslami perspektiften bakıldığında, ilgili metinlerde nakledilen hadislerin en meşhurları şunlardır: 
Ebû Davûd'un rivayeti şöyledir: "Medine'de bir kadın (Ümmü Atiyye) kızları sünnet ediyordu. Hz. Muhammet ona: 'Fazla derin kesme; çünkü derin kesmemen, hem kadın için ahzâ (en ziyade haz ve lezzet vesilesi) hem de kocası için daha hoştur' dedi." Hz. Aliden rivayet edildiği üzere ise, Hz. Muhammet birini yollayarak sünnetçi kadını çağırır ve "Sünnet ettiğin zaman üstten hafifçe kes, fazla dipten kesme..." der. Bir başka rivayette ise Hz. Peygamber, "Ey Ensar kadınları! .... Sünnet olun, fakat aşırıya kaçmayın, size verilen nimetlere nankörlük etmekten uzak durun" diye buyurmaktadir.

"Sünnet olmak erkek için 'sünnet', kadın için 'mekrume' (faziletli bir amel) niteliğindedir” (Ahmed b. Hanbel, Ebû Dâvûd) gibi aktarımlar mevcuttur. Ancak Kur’an'da kızların sünnetine mesnet teşkil edip hüküm çıkarılacak bir ayet yoktur. Kız sünnetinden bahseden hadisler, hadis ulemasınca zayıf bulunmuştur. Fetva vermeye mesnet olacak sihhat ve kuvvette kabul edilmemiştir. Hz. Muhammet ve Hz. İbrahim'in kızlarına ve kız torunlarına sünnet emretmediği ve yaptırmad1ğı bilinmektedir. Öte yandan, sünnetle ilgili kaynaklarda zikredilen "fitrat," "şiar," "mekrume" ifadelerinin hiçbiri, İslam hukuk sisteminde sünnetin mecburiyetine mesnet teşkil etmez (8).

Kız sünneti hakkında klasik fukaha görüşü; Şafiîlerde "vacip;" Hanefî, Malikî ve Hanbelîlerde ise "sünnet" şeklindedir. Ancak, çağdaş tıbbi bilgi ve gelişmeler ışığında, sünnetin kadının ruh, beden ve cinsel sağlığı üzerindeki zararlı etkileri dikkate alınarak, bu görüşler kabul edilmemelidir. Çoğunluk itibarıyla çağdaş fukaha kız sünnetini "caiz" veya "mübah" olarak nitelemektedir. İşlemin, kadının sağlığı için önemli bir tehlike arz ediyorsa "mekruh," hayatı için ciddi bir tehdit teşkil ediyorsa "haram" olduğu yönünde fetva verilir $(34,35)$.

Yukarıda tarifini verdiğimiz "hoodectomy" ise, fıkhi açıdan da farklı değerlendirilmelidir. Zira sadece klitorisi örten sünnet derisinin bir kısmını almak suretiyle (erkek sünnetine benzer şekilde) gerçekleştirilen bu işlem;

- Zararsizdir,

- Faydalıdir,

- Kadın ve erkek için cinsel zevk ve mutluluğu artıricidir.

"Hoodectomy" nakledilen hadislerdeki ifadelere

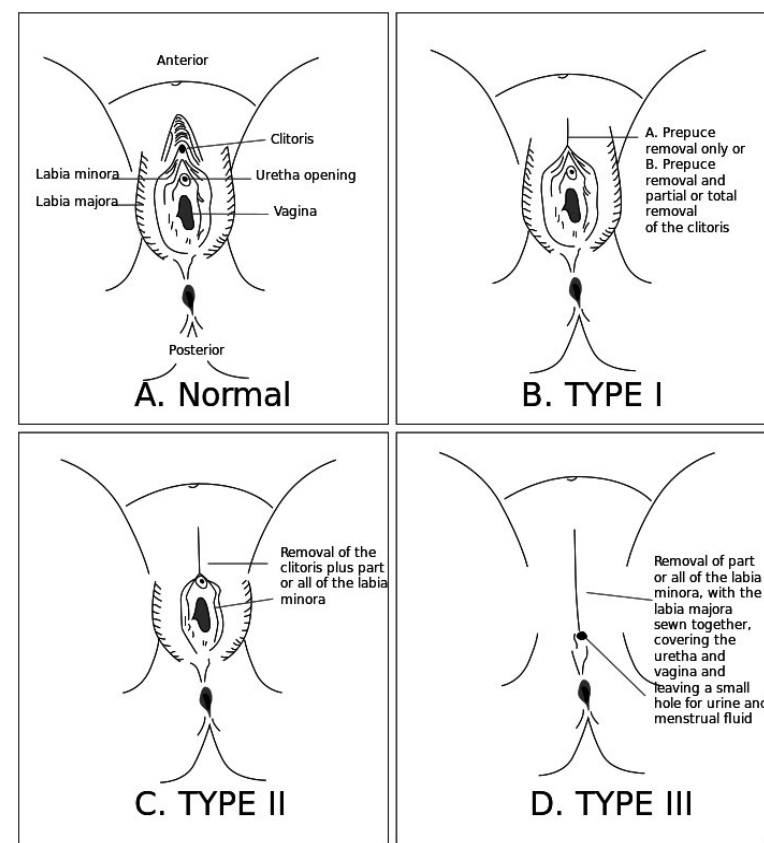

Resim 2. Dünya Sağlık Örgütü’nün kadın sünneti tasnifi

mantık, bilim ve tecrübe açısından muvafıktır. Çünkü bu müdahalede abartı yoktur; işlem kadın ve erkek için iyi ve zevk verici olup mekrume niteliğindedir.

Kadın sünnetiyle ilgili güncel fikhi perspektifi, ülkemizden Prof. Dr. Hayreddin Karaman ve İslam dünyasından alim Yusuf el-Karadavînin görüşleri ile özetleyebiliriz. Karaman şöyle demektedir (36):

"Bazı topluluklarda uygulanan bir adet var; genç kızların klitoris (bızır) adı verilen organlarını tamamen veya kısmen kesmek; buna kızların sünneti deniyor ve en azından Misır firavunları devrinden beri bazı yerlerde uygulandığı biliniyor.

Erkeğin sünnetinin etkisi hem temizlik hem de haz bakımından olumlu ve faydalı olduğu halde kızların 'sünneti'nin hiçbir faydası yok, üstelik önemli zararlar1 var ve adeta -kızlar azmasın, iffetlerini korusunlar diye- onları sakat etmek, yaratılıştan mevcut ve önemli işlevleri bulunan bir organı yok etmek söz konusu.

İslam dışı toplulukların İslam’a mal ederek istismar ettikleri konulardan biri de bu 'kızların sünneti' meselesidir. Kur'an'da, sahih ve açlk ifadeli hadisler arasında, icmada ve kıyasta 'İslami bir gereklilik olarak' yer almadığı halde bu operasyonu dine mal etmek haksızlıktır; savunmak da yersiz, hatta zararlı bir davranıştır.

Oğlum ürolog olduğu için aramızda bu konuyu yıllardır konuşmuşuzdur. Normal bir klitorisi kısmen veya tamamen kesmeyi tıp sakıncalı buluyor ve asla 
faydasından söz edilmiyor. Müslüman halklar ise zaten genellikle bunu uygulamıyorlar. Günümüzde belki de yalnızca bazı Afrika, Orta Doğu, Uzak Doğu ülkelerinde kısmi uygulamalar var.

Benim okumalarım sonunda ulaştı̆̆ım kanaat şu idi: İslam'da, 'kızların sünneti diye bir dini uygulama' yoktur; bunu öteden beri bazı topluluklar bir âdet olarak uygulamışlardır; Peygamber (SA) zamanında da halk, makbul bir âdet (mekrume) olarak bunu uygulamakta idi; Efendimiz bunu yapanlara klitorisin faydalarını hatırlatarak 'aşırıya kaçmayın' tavsiyesinde bulundu.

İslam muhaliflerinin istismar ettikleri bazı konuları sirayla ele almaya niyet edince bu konuya yeniden eğildim. Çağdaş alimlerden Yusuf Karadâvînin sitesinde aynı kanaati paylaştığını ve bu işi din adına savunanların dayanaklarını çürüttüğünü gördüm.

Ayrica 22-23/11/2006 tarihinde, el-Ezher Üniversitesi’nin himayesinde dünyanın çeşitli ülke ve bölgelerinden gelen birçok alimin ve uzmanın katıldığı bir ilmi toplantı yapıldığına muttali oldum. Bu toplantıda alınan kararların önemli maddeleri şöyledir:

1. Allah, erkek olsun kadın olsun insanı değerli ve dokunulmaz kılmıştır.

2. Kızların sünneti, Kur'an’a veya sahih sünnete dayanmadan bazı kimselerin, âdete uyarak yaptıkları bir uygulamadir.

3. İslam insana maddi veya manevi zarar vermeyi yasaklamıştır. Bu âdetin kadınlara maddi ve psikolojik olarak önemli zararları vardır.

4. Toplantıya katılan heyet Müslümanlara, bu zararlı uygulamadan vazgeçmelerini, halkın bilgi ve şuur edinmesi için gayret edilmesini ve yönetimlerin de kanuni tedbirler almasinı tavsiye eder." Karadâvînin görüşleri ise aşağıdaki gibidir:

- Kızların sünnetinin farz, vacip, müstehap olduğuna dair Kitap, sünnet, icma ve kıyastan delil yoktur.

- İlgili hadisler (rivayetler) ya zayıftır ya da bağlayıcı bir hüküm getirmez.

- Bu iş olsa olsa "sakıncası yoksa caiz" hükmüne girer.

- İslam'dan öncesinden beri bazı kabileler bunu adet edinmişlerdi, Hz. Muhammet âdet olduğu için menetmemiştir, ancak "aşırı gitmeyin / abartmayın" buyurmuştur.

- Bugün ümmet genel olarak kızların sünnetini terk etmiştir.
- Tip otoriteleri de bunun -özellikle klitoristen kesmenin- zararlı olduğunda birleşmektedir.

- Bu sebeple "zararı görüldüğünde, caiz olan bir şeyin ulu'l-emr tarafından yasaklanması caizdir” kuralına göre bu işlem menedilmelidir.

\section{Sonuç}

Kadın sünnetinin esasen sosyokültürel mitlerden ileri geldiğini, tıp ahlakı ile bağdaşmadığını ve herhangi bir tıbbi, sıhhi yararı da olmadığını belirttikten sonra, dini/İslami netice olarak da Prof. Dr. Hayreddin Karaman’ın varmış olduğu neticeyi (36) yeniden arz etmek uygundur: İslam "kızları sünnet" diye bir dini vazife getirmemiş, bunu tavsiye ve teşvik dahi etmemiştir. Keza eski fıkıhçılar da vacip, caiz, müstehap gibi farklı içtihatlar ileri sürmüş, bunun "İslami bir vazife" olduğu hükmünde birleşmemişlerdir. Şu halde İslam, "İslam'da kızların sünneti var, bu ise eziyettir, cinayettir, vahşettir...” şeklindeki itham ve iftiralardan münezzehtir.

\section{KAYNAKLAR}

1. Birleşmiş Milletler Çocuk Fonu (UNICEF). Female Genital Mutilation/Cutting: A statistical overview and exploration of the dynamics of change. Erişim: www.unicef. org/publications/index_69875.html, erişim tarihi: 10.12 . 2016.

2. Birleşmiş Milletler Çocuk Fonu (UNICEF). The State of the World's Children 2015: Executive Summary. Erişim: www.unicef.org/publications/files/SOWC_2015_Summary_and_Tables.pdf, erişim tarihi: 20.12.2016.

3. Wikimedia Commons. FGM prevalence UNICEF 2015. Erişim: https://commons.wikimedia.org/wiki/ File:FGM_prevalence_UNICEF_2015.svg, erişim tarihi: 20.12.2016.

4. Oringanje CM, Okoro A, Nwankwo ON, Meremikwu MM. Providing information about the consequences of female genital mutilation to healthcare providers caring for women and girls living with female genital mutilation: a systematic review. Int J Gynaecol Obstet. 2017;136(Suppl 1):65-71.

5. Perron L, Senikas V, Burnett M, Davis V. Excision génitale féminine. J Obstet Gynaecol Can 2016;38(12S):S348 S369.

6. The National Health Service. Female genital mutilation 
(FGM). Erişim: www.nhs.uk/Conditions/female-genital-mutilation, erişim tarihi: 10.01.2017.

7. Pearce AJ, Bewley S. Medicalization of female genital mutilation. Harm reduction or unethical? Obstet Gynaecol Reprod Med. 2014;24(1):29-30.

8. Serour GI. Medicalization of female genital mutilation/ cutting. Afr J Urol. 2013;19(3):145-9.

9. Morlin-Yron S. Cut in secret: the medicalization of FGM in Egypt. CNN Africa. 7 Şubat 2017.

10. Shell-Duncan B. The medicalization of female "circumcision": harm reduction or promotion of a dangerous practice? Soc Sci Med. 2001;52(7):1013-28.

11. Topping A, Carson M. FGM is banned but very much alive in the UK. The Guardian. 6 Şubat 2014.

12. Dorkenoo E, Morison L, Macfarlane A. A Statistical Study to Estimate the Prevalence of Female Genital Mutilation in England and Wales: Summary Report. Londra: Foundation for Women's Health, Research and Development; 2007.

13. Biglu MH, Farnam A, Abotalebi P, Biglu S, Ghavami M. Effect of female genital mutilation/cutting on sexual functions. Sex Reprod Healthc. 2016;10:3-8.

14. Bazi T. Female genital mutilation: the role of medical professional organizations. Int Urogynecol J. 2017;28(4):537-41.

15. Jurnalis Uddin ve ark. (ed.), Female Circumcision: A Social, Cultural, Health and Religious Perspectives. Cakarta: Yarsi University Press; 2010.

16. Dünya Sağlık Örgütü. WHO Guidelines on the Management of Health Complications from Female Genital Mutilation. Cenevre: Dünya Sağlık Örgütü; 2016.

17. Bishai D, Bonnenfant YT, Darwish M, Adam T, Bathija $\mathrm{H}$, Johansenc E ve ark. Estimating the obstetric costs of female genital mutilation in six African countries. Bull World Health Organ. 2010;88:281-8.

18. Wikimedia Commons. FGC types. Erişim: https://commons.wikimedia.org/wiki/File:FGC_Types.jpg, erişim tarihi: 13.02.2017.

19. Refaei M, Aghababaei S, Pourreza A, Masoumi SZ. Socioeconomic and reproductive health outcomes of female genital mutilation. Arch Iran Med. 2016;19(11):805-11.

20. Holmes V, Farrington R, Mulongo P. Educating about female genital mutilation. Educ Prim Care. 2017;28(1):36.

21. Vogt S, Mohmmed Zaid NA, El Fadil Ahmed H, Fehr E, Efferson C. Changing cultural attitudes towards female genital cutting. Nature. 2016;538(7626):506-9.

22. Abdulcadir J, Rodriguez MI, Say L. Research gaps in the care of women with female genital mutilation: an analy- sis. BJOG. 2015;122(3):294-303.

23. Yount KM, Carrera JS. Female genital cutting and reproductive experience in Minya, Egypt. Med Anthropol Q. 2006;20(2):182-211.

24. Dünya Sağlik Örgütü. Female genital mutilation fact sheet. Erişim: www.who.int/mediacentre/factsheets/ fs241, erişim tarihi: 02.03.2017.

25. Clarke E. Female genital mutilation: a urology focus. $\mathrm{Br}$ J Nurs. 2016;25(18):1022-8.

26. Dünya Sağlık Örgütü. Eliminating Female Genital Mutilation: An Interagency Statement. Cenevre: World Health Organization; 2008.

27. Dünya Sağlık Örgütü. A Systematic Review of the Health Complications of Female Genital Mutilation including Sequelae in Childbirth. Cenevre: World Health Organization, 2000.

28. Larsen U, Okonofua FE. Female circumcision and obstetric complications. Int J Gynaecol Obstet. 2002;77(3):255-65.

29. Zeplin PH. Clitoral hood reduction. Aesthet Surg J. 2016);36(7):NP231.

30. Hunter JG. labia minora, labia majora, and clitoral hood alteration: experience-based recommendations. Aesthet Surg J. 2015;36(1):71-9.

31. Placik OJ, Arkins JP. A prospective evaluation of female external genitalia sensitivity to pressure following labia minora reduction and clitoral hood reduction. Plast Reconstr Surg. 2015;136(4):442e-52e.

32. Beauchamp TL, Childress JF. Biyomedikal Etik Prensipleri, çev. M. Kemal Temel. İstanbul: BETIM; 2017.

33. Dünya Sağlık Örgütü. Management of Pregnancy, Childbirth and the Postpartum Period in the Presence of Female Genital Mutilation. Cenevre: World Health Organization, 1997.

34. El-Ahl A. A Small Revolution in Cairo: Theologians Battle Female Circumcision. Spiegel, 6 Aralık 2006.

35. Menka E. Islam does not support female circumcision. GhanaWeb, 16 Mart 2005.

36. Karaman H. Kızların sünnet edilmesi yok. Erişim: www. hayrettinkaraman.net/makale/0621.htm, erişim tarihi: 25.02.2017. 